\title{
Using Wikis to Enhance Website Peer Evaluation in an Online Website Development Course: An Exploratory Study
}

\author{
Wu He \\ Department of Information Technology and Decision Sciences, \\ Old Dominion University, Norfolk, Virginia, USA
}

\author{
whe@odu.edu
}

\section{Executive Summary}

Peer evaluations are often used to improve learning in educational settings. As more and more online courses are offered, it is becoming increasingly important to explore new techniques for conducting peer evaluation in online courses. In recent years, wikis have increasingly been used in higher education to support learning and group work. However, the number of studies that discuss the use of a wiki as a peer evaluation tool in online courses is still rather limited. This paper examines the effect of using a wiki as an online peer evaluation tool and identifies the pedagogical benefits and pitfalls of using wikis for peer evaluation activities. It describes a study in which wikis were used as a means to support peer evaluation in an undergraduate online website development course. Students were assigned to groups. Each member performed a peer evaluation of the websites of every other student in the group. At the end of the study, the author surveyed students using an online questionnaire and also examined the information listed on each group's wiki website. The study concludes that wikis are an effective tool for conducting peer evaluation in online courses. A key lesson learned is that website peer evaluations can also be a very strong learning activity for online website development courses -- but that the success of this activity highly depends on the people involved in the peer group. Recommendations regarding group formation, coordination, and motivational strategies are offered to assist instructors who are interested in using wikis for their students to perform peer evaluations. Overall, this paper provides some evidence of the ways that wikis can be used to help faculty conduct peer evaluation activities in an online environment and contributes to the body of evidence regarding the use of wikis in online education.

Keywords: Peer Evaluation, Peer review, Collaborative Learning, Wiki, Web Development, Online courses

\section{Introduction}

Material published as part of this publication, either on-line or in print, is copyrighted by the Informing Science Institute. Permission to make digital or paper copy of part or all of these works for personal or classroom use is granted without fee provided that the copies are not made or distributed for profit or commercial advantage AND that copies 1) bear this notice in full and 2) give the full citation on the first page. It is permissible to abstract these works so long as credit is given. To copy in all other cases or to republish or to post on a server or to redistribute to lists requires specific permission and payment of a fee. Contact Publisher@InformingScience.org to request redistribution permission.
Many studies have shown that peer evaluation is an accepted and useful method for learning (Skeele, 2009; Wessa \& De Rycker, 2010). Various professions use regular peer evaluation as a way to improve the quality of products or artifacts (Cho \& Schunn, 2005; Mirielli, 2007; Snodgrass, 2006; Thomas, Davis, \& Kazlauskas, 2007). 
In recent years, many courses have been offered in an online format. To facilitate online peer evaluation in education, some specific online software tools such as PASS (Li \& Steckelberg, 2005), Aropa (Hamer \& Sword, 2007), SWoRD (Cho \& Schunn, 2005), eSpace (De Volder et al., 2007) and Waypoint (Skeele, 2009) have been developed during the past decade. However, these products were mainly developed in-house by specific universities and are often either not available or are not free to instructors/students outside of those universities. In some cases, the tools have become obsolete due to lack of update and maintenance. Thus, it seems a natural choice to leverage free Web 2.0 tools such as wikis for peer evaluation.

Recent publications suggest the use of wiki technology to support online teaching strategy and promote student interaction is gaining ground (Dishaw, Eierman, Iversen, \& Philip, 2011; Kane, \& Fichman, 2009; Lending, 2010; Otter, Whittaker, \& Spriggs, 2009; Park, Crocker, Nussey, Springate, \& Hutchings, 2010; Roussinos \& Jimoyiannis, 2011; Tsai, Li, Elston, \& Chen, 2011). However, not all uses of wikis in online learning environments have been successful (Elgort, Smith, \& Toland, 2008). Bower, Woo, Roberts, and Watters (2006) point out that the collaborative nature of the learning task and the task authenticity are success factors in using wikis. Raman, Ryan, and Olfman (2005) suggest that success in using wikis for collaborative activities may depend on familiarity with wiki technology, careful planning for implementation and use, appropriate class size, and the motivation of the students in discovery learning. In addition, Tsai et al. (2011) identify six factors that are critical to make the wiki approach successful: knowledge base, motivation, social aspects, presentation, feedback, and support.

Skeele (2009) suggests that educators should continue to explore the blending of peer evaluation and new technologies to enhance teaching and promote learning. In their case study investigating the mechanics of incorporating peer review in an online course, Knight and Steinbach (2011) found that "electronic reviews for an online class are far more complex to orchestrate than similar reviews administered using paper in a traditional classroom. Minor procedural steps that easily are made both unambiguous and obligatory in a paper-based classroom peer review became far more difficult to implement online."

Thus, to examine the effect of using wikis as an online peer evaluation tool and to identify the pedagogical benefits and pitfalls of using wikis for peer evaluation activities, the author conducted a study to evaluate the use of wikis in supporting peer evaluation activities in an online undergraduate website development course. In particular, the author was interested in how members in a team conducted peer evaluation on individual efforts in a personal website development project using wikis. This study explored undergraduate students' perceptions of Wikis as peer evaluation tools and aimed to further contribute to the body of knowledge regarding the use of wikis in higher education.

\section{Study Design}

\section{Context of the Study}

An introductory website development course is offered to students (both IT majors and non-IT majors) at our university each year. This course is delivered in an online format with the use of Blackboard. Students taking this course are juniors and seniors from a variety of majors including information technology, finance, education, health science, fine art, psychology, and political science. The course covers such topics as HTML/XHTML, CSS, JavaScript, the basics of PHP language, and the principles of usability and user interface design. The learning goal is to enable students to design and develop aesthetically pleasing and functional websites with a user-centered perspective. 
The participants in this study included students enrolled in 300-level website development courses during the Fall 2010 session. There were a total of 38 students enrolled in this online course -- 12 female students and 26 male students. Seventeen of the students were Information Technology Majors, six were Computer Science Majors, and 15 represented other majors such as Finance, Fine Arts, and Human Services. In the 'first day of the semester survey' administered by the instructor, the majority of students identified themselves as strongly computer literate and familiar with Blackboard (the learning management system used at the university). Most of them reported that this was the first time they were taking an online course.

One of the course projects required that each student create a small-scale website for the topic of their choice. For example, a student could create a website for a student club/organization, a school, a restaurant, a company, a tourism destination, a business product, etc. As part of the technical requirements, the website assignment required developing at least 8 web pages, using Cascading Style Sheets and a consistent navigation scheme. However, before the students implemented their websites, they needed to submit a proposal about their selected topic to their instructor for approval. The proposal needed to address the following items:

- What is the purpose of the site?

- What do you want the web site to accomplish?

- Who is your intended audience?

- What opportunity, problem, or issue is your site addressing?

- What type of content might be included in your site?

- List at least two related or similar sites found on the Web.

Once their proposal was approved by the instructor, each student created a storyboard about their website and submitted it to the instructor for review. The storyboard usually consisted of a series of pages that included a rough sketch outlining the content, navigation, and design elements of the proposed website. After the storyboard was approved, students had about two weeks to implement the website using the web technologies that they had learned in the class (such as HTML/XHTML, CSS, JavaScript, and PHP).

After students completed the website development and submitted their website URL to the instructor, they were randomly allocated to one of eight groups for the peer evaluation of their websites. Each group included four or five students. Each group was asked to create a wiki site at wikispaces.com and to use the group wiki site to conduct its website peer evaluation using the evaluation criteria provided by the instructor below (see the Appendix to see the full assignment provided to the students):

- How well is the material/content presented?

- Is the information clear?

- Is the website easy to navigate?

- Is the site aesthetically pleasing?

- What improvements still need to be made to the site?

Each group was given a week to complete the peer evaluation activities. Students were encouraged to follow up and provide responses to the feedback they received and/or seek clarification when the feedback was not clear and understandable. Students were told that their participation and contribution in the peer evaluation activity would be graded. This website peer evaluation activity was worth $3.33 \%$ of the overall course grade. After the peer evaluation process, students were allowed to make changes to their website based on the feedback they received before a specified deadline. At the end of the project, the instructor graded each student website. The overall process for the website development project is shown in Figure 1. 


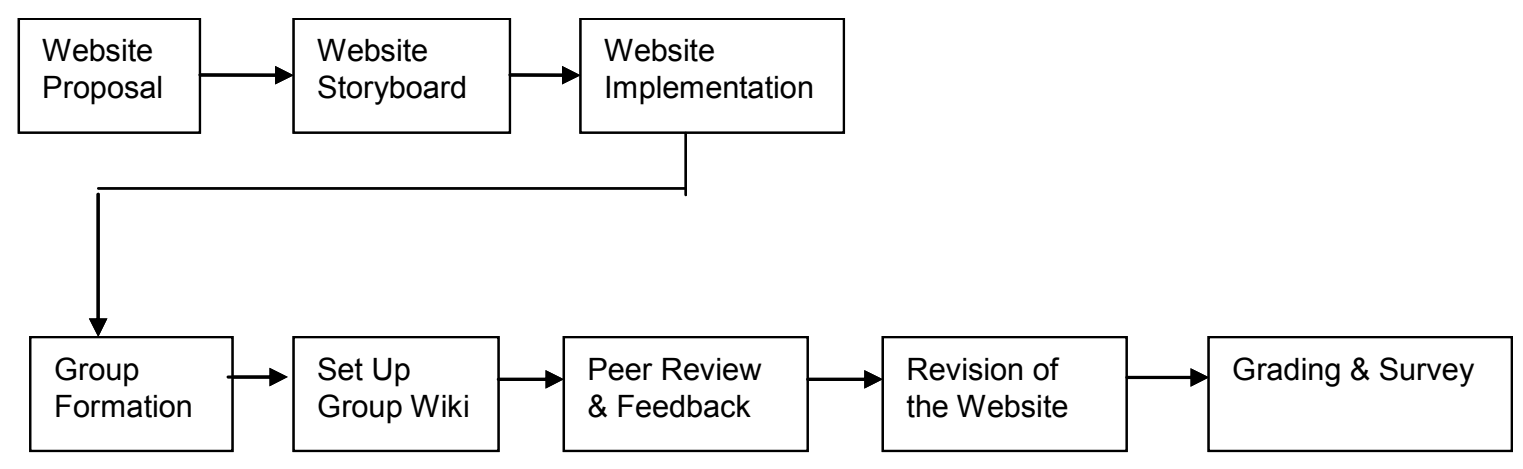

Figure 1: Project Design

Wikis were used as a tool for peer evaluation in this study. A wiki is a web site that allows for collaboration from a group of users who can add, remove, edit, and change the content of web pages within the site (Dishaw et al., 2011; Tsai et al., 2011). A wiki can be "closed" (private, only open to certain users), or "open" (everyone on the Internet can have access). A group of users can achieve a consensus on the content of a wiki item, with all the change history recorded. Therefore, the author considered a wiki particularly suitable for a group of students to conduct the online peer evaluation.

A wiki can easily be created using software such as wikispaces.com or mediawiki. The author decided to pick wikispaces for the study because wikis at wikispaces have many user-friendly features and are also free to educators and students. For example, all wikis at wikispaces offer features including easy WYSIWYG editing, unlimited members, unlimited pages, large file storage, built-in discussion forums, and reliable technical support services. Particularly, the built-in discussion forums allow participants to post new messages, follow up to existing ones, and engage in text-based conversation organized into discussion threads. Figure 2 shows a screenshot of a generic wiki site at wikispaces.com.

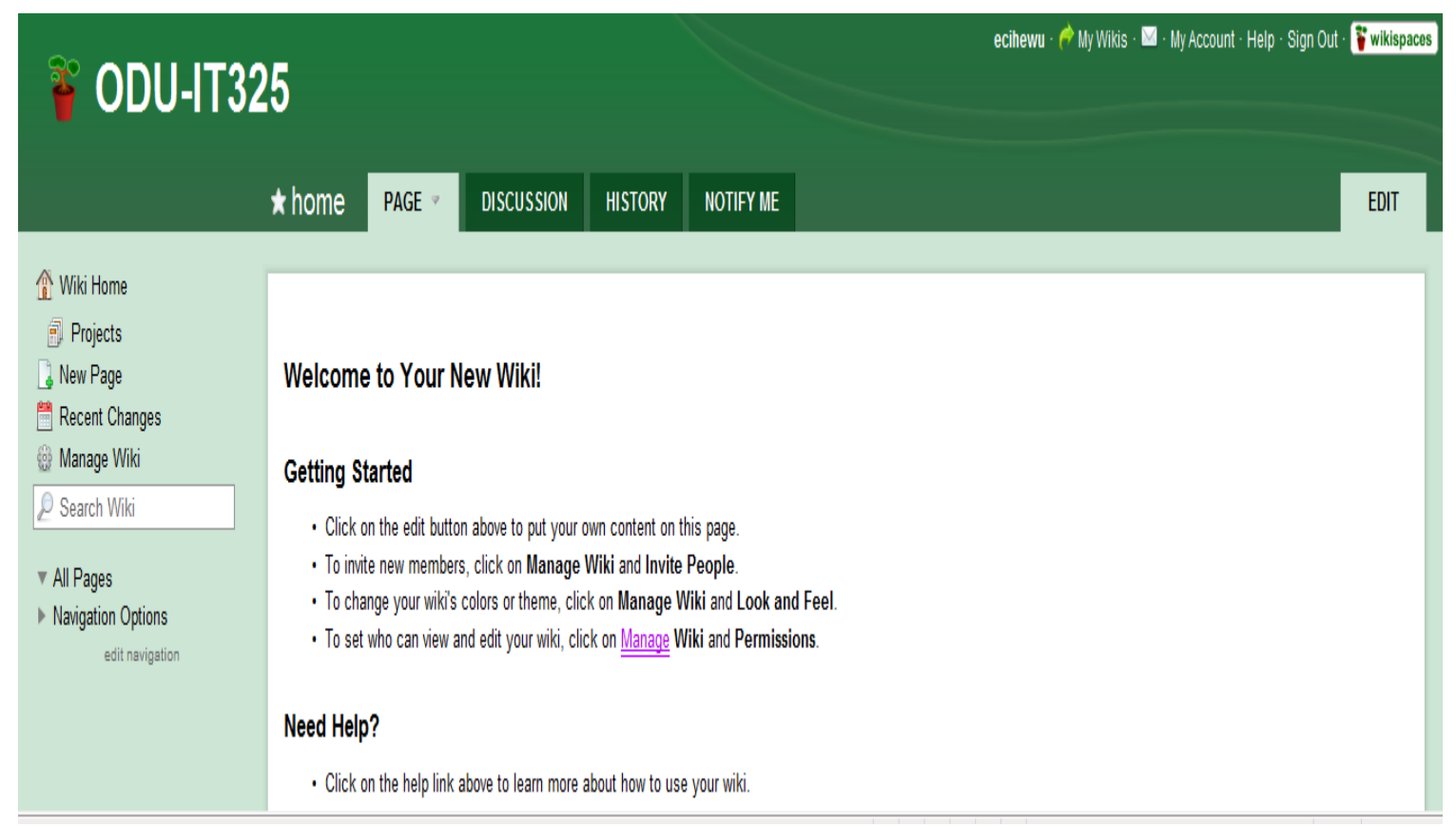

Figure 2: A screenshot of a wiki site at wikispaces.com 


\section{Data Collection and Analysis}

The instructor collected data using multiple methods. Students completed an online survey questionnaire that included four structured questions (see Table 1) and a single request for open-ended comments. A five-point Likert scale (strongly agree, agree, neutral, disagree, and strongly disagree) was used for the structured questions. Student participation in this survey was anonymous and voluntary.

\begin{tabular}{|l|l|l|l|l|l|}
\hline \multicolumn{2}{|c|}{ Table 1: Student Response (N=26) } \\
\hline Statement & SD & D & U & A & SA \\
\hline I found it easy to work with the wiki. & $0 \%$ & $0 \%$ & $3.8 \%$ & $50 \%$ & $46.2 \%$ \\
\hline $\begin{array}{l}\text { The wiki tool has all the functions and capabilities I ex- } \\
\text { pect it to have for completing this website peer review } \\
\text { assignment. }\end{array}$ & $0 \%$ & $0 \%$ & $7.7 \%$ & $57.7 \%$ & $34.6 \%$ \\
\hline $\begin{array}{l}\text { The peer feedback on the wiki helped me improve my } \\
\text { website. }\end{array}$ & $3.8 \%$ & $7.7 \%$ & $19.2 \%$ & $42.3 \%$ & $26.9 \%$ \\
\hline $\begin{array}{l}\text { The use of a wiki for the website peer review is a good } \\
\text { idea. }\end{array}$ & $3.8 \%$ & $11.5 \%$ & $3.8 \%$ & $42.3 \%$ & $38.5 \%$ \\
\hline
\end{tabular}

To enrich the findings and to get better understanding about the students' experience in using wikis for this peer evaluation task, the author also reviewed each group's wiki website, examining the information listed on each wiki website including the pages, discussion posts, files, change histories, and wiki statistics, thus both quantitative and qualitative data were collected from the wiki websites. This analysis revealed that six students did not participate in the peer evaluation. Thus, the author had to exclude the six students from our data analysis. After the instructor completed the grading for each website, the grades were also added to the data set.

The student survey was administered using SurveyMonkey, an online survey and questionnaire tool. This tool provides a user-friendly way for the researchers to analyze individual responses, to view details from a particular respondent, to read the comments of open-ended questions, or to view the summary report of the survey results, in real time.

The author reviewed student comments in the survey responses carefully and summarized the key findings. The evaluation of the quantity and quality of student participation conducting the peer evaluations provided greater insight into student comments.

\section{Results}

A total of 26 students out of the 32 participating students responded to the survey with a response rate of $81 \%$. Overall, most students were quite positive about their experience using a wiki as a tool for peer evaluation (See Table 1). They reported that it was easy to work with wikis $(96.2 \%)$. $92.3 \%$ of students agreed or strongly agreed that the wiki tool had all the functions and capabilities they needed for completing this website peer review assignment. $69.2 \%$ of students agreed or strongly agreed that the peer feedback on the wiki helped them improve their website. Some students commented that they received helpful feedback or good ideas that helped them to improve their website. For example, a student said that his teammate found several broken links that he had overlooked on his website. However, two students mentioned that the feedback that they received was either superficial (e.g., how pretty the color scheme was) or too critical (they didn't know how to fix it). One student indicated that "it really depends on who you have on your team. Not really wiki's responsibility on whether if you get productive feedbacks that can help you im- 
prove your site." $80.8 \%$ of students thought that the use of a wiki for the website peer review was a good idea (80.8\%). But three students mentioned that it was not easy to get everyone to sign up for the wiki site at the beginning (e.g., responding back and forth to e-mails until everyone got on it) and suggested using the discussion forum in Blackboard instead.

When participants were asked what issues and additional comments they had with this website peer review assignment, 16 students answered this open-ended question. Nine students reported the issues they had experienced in using the wiki tool to complete this website peer review assignment. The issues were categorized into three areas (See Table 2).

\begin{tabular}{|c|c|}
\hline \multicolumn{2}{|r|}{ Table 2: Issues reported by students } \\
\hline Issues & Student Comments \\
\hline People issue & $\begin{array}{l}\text { - Students waiting till a few hours before the assignment deadline to post } \\
\text { their comments; } \\
\text { - I commented and nobody would respond; } \\
\text { - I think some of the peers were too critical of other work and did not care } \\
\text { what they say; } \\
\text { - The wiki tool is not the problem. The problem is getting the group started. }\end{array}$ \\
\hline Technology issue & $\begin{array}{l}\text { - The member name on the wiki makes it hard to determine who said what; } \\
\text { - The wiki editor did not allow font changes but it was WYSIWYG. So when } \\
\text { I pasted text in, the font ended up different than the rest of the page; }\end{array}$ \\
\hline $\begin{array}{l}\text { Process/Logistics } \\
\text { issue }\end{array}$ & $\begin{array}{l}\text { - "preferred contact method" e-mail addresses need to be provided for each } \\
\text { group member when the groups are formed so everyone knows how to get } \\
\text { in touch quickly; } \\
\text { - Ifind it hard to know who does what editing on the wiki because it is so } \\
\text { free to anyone if it's a public wiki. It can make it hard to control what is } \\
\text { going on with the group. } \\
\text { - Just initially, it was a bit confusing on how to do what first and so on. I } \\
\text { think it would be good idea for beginners who have never used wiki be- } \\
\text { fore, a little startup steps to get things going. }\end{array}$ \\
\hline
\end{tabular}

Overall, ten students indicated that this assignment provided them with a valuable learning experience. They reported that the experience with the peer review was great and they enjoyed this activity. They thought that the peer evaluation gave them the opportunity to correct mistakes and offered them an outside view of their web pages. Three students suggested using the discussion forum in blackboard for peer evaluation because it does not require extra account setup or configuration. One student provided suggestions for the grouping process. His/her comment is listed as follow:

Peer review is good idea but always depends on the people involved in a group. Before assigning peers, it might be good idea to run through quick evaluation and put at least one or two good students in each group. "Good" students can be evaluated by their grade progress in the class.

In addition to the analysis of the survey responses, the author also analyzed the data that the author collected from each group's wiki website. It was interesting to discover that groups had used four different ways to conduct the peer evaluation activity. 
1) Four groups (Groups 1, 3, 5, and 7) used the 'multiple wiki pages' approach. Three out of the four groups (Groups 1,3, and 5) created a wiki page for each website and then posted their evaluation results of that website directly onto that wiki page. On their pages, each page usually contained information such as the URL of the website, the name of the author, and a short description of the website. However, Group 7 was an exception. The members of Group 7 created their wiki page in a different way. Each student in Group 7 created a wiki page for himself or herself and posted evaluation results of other group members' websites on the page.

2) Two of the eight groups (Groups 4 and 6) used the discussion forum associated with the homepage provided by the wiki. In the discussion forum, they created a thread for each student's website to gather feedback.

3) One group (Group 2) used the discussion forum associated with the homepage provided by the wiki. However, in the discussion forum, they only created one thread for all the members. That means that all of the feedback was saved in one large post.

4) One group (Group 8) used the 'multiple wiki pages and multiple discussion forums' approach. They created a student page for each member in the group respectively and then posted their evaluation result on the discussion forum associated with each page.

The diversity of the peer evaluation approach shows that students had more control over the way in which peer evaluation was conducted than if they had used discussion forums in Blackboard, since wikis can be configured in different ways to meet students' needs and preferences.

\begin{tabular}{|l|l|l|}
\hline \multicolumn{3}{|c|}{ Table 3: Group Peer Evaluation Overview } \\
\hline Group & Peer Evaluation Approach & Total Messages \\
\hline Group 1 (4 students) & Multiple Wiki Pages & 18 (posted by 4 students) \\
\hline Group 2 (4 students) & $\begin{array}{l}\text { One Discussion forum with only } \\
\text { one thread }\end{array}$ & 12 (posted by 3 students) \\
\hline Group 3 (5 students) & Multiple Wiki Pages & 14 (posted by 3 students) \\
\hline Group 4 (5 students) & $\begin{array}{l}\text { One Discussion forum with mul- } \\
\text { tiple threads }\end{array}$ & 9 (posted by 3 students) \\
\hline Group 5 (5 students) & Multiple Wiki Pages & 12 (posted by 4 students) \\
\hline Group 6 (5 students) & $\begin{array}{l}\text { One Discussion forum with mul- } \\
\text { tiple threads }\end{array}$ & 26 (posted by 5 students) \\
\hline Group 7 (5 students) & Multiple Wiki Pages & 15 (posted by 5 students) \\
\hline Group 8 (5 students) & $\begin{array}{l}\text { multiple wiki pages and multiple } \\
\text { discussion forums }\end{array}$ & 37 (posted by 5 students) \\
\hline
\end{tabular}

Table 3 shows that some groups were more active than other groups in terms of the messages they posted during the peer evaluation process. Students brought different levels of web technology skills to the class. While most students were quite new to web development prior to the class, several students apparently had prior experience in web development. The author found that their web development experience had a large impact on the quality of each group's peer evaluation activity. One student was eager to help others in the group fix issues with their websites and made multiple posts with lengthy explanations including sample codes and examples, in order to answer questions from his/her peers and to guide them to improve their websites. The posts made by this student demonstrated a higher level of web development experience than his/her peers and made a crucial contribution to the group peer evaluation activity. 
The interaction among peers was also important to the success of the peer evaluation activity. One student indicated that nobody responded to his comments, which discouraged him from making more contributions. The author also noticed that a few students posted their evaluation comments several hours before the deadline, which made the peer evaluation activity less meaningful and useful to classmates. Further analysis and comparison of the posts in each group revealed that the quality of the group peer evaluation activity really depended upon the experience and motivation of members in each group as well as the interactions among the peers. It also appeared that some groups were more organized than others and conducted the peer evaluation activity with effective planning and coordination. This finding further confirmed that using a wiki is no guarantee that individuals will work together as a group (Elgort et al., 2008).

To produce high quality group work, more careful considerations about the group's formation and motivational strategies are needed. For example, one student suggested assigning peers into groups based on their prior class performance (such as their grade progress in the class) to ensure that at least one or two 'good' students would be in each group. To better encourage students to engage into the peer evaluation and collaboration, motivational strategies (such as giving a grading bonus for the best peer evaluator in each group) might be very helpful.

The content analysis of the actual student postings on the various wikis/forums identified a few emergent themes, and the author was able to classify these messages into the following categories (See Table 4).

\begin{tabular}{|c|c|c|}
\hline Category & Themes & Examples or explanations \\
\hline $\begin{array}{l}\text { Evaluation com- } \\
\text { ments \& feedback }\end{array}$ & - & $\begin{array}{l}\text { Students posted their evaluation comments and feed- } \\
\text { back based on the evaluation criteria given by the in- } \\
\text { structor. }\end{array}$ \\
\hline \multirow[t]{6}{*}{$\begin{array}{l}\text { Reply to the evalu- } \\
\text { ation comments }\end{array}$} & $\begin{array}{l}\text { Questions (Asking for cla- } \\
\text { rification, etc) }\end{array}$ & $\begin{array}{l}\text { Do either of know where I might be able to find the } \\
\text { requirements? } \\
\text { Where is this "Achievement" link under? I don't re- } \\
\text { member having one. }\end{array}$ \\
\hline & $\begin{array}{l}\text { Acknowledgement (ac- } \\
\text { knowledging other par- } \\
\text { ticipants' contributions and } \\
\text { ideas) }\end{array}$ & $\begin{array}{l}\text { Thank you both for the wonderful comments and sug- } \\
\text { gestions! I'll get right on that to fix them for my site; }\end{array}$ \\
\hline & $\begin{array}{l}\text { Providing explanation } \\
\text { and/or justification. }\end{array}$ & $\begin{array}{l}\text { I only have a small, non-widescreen laptop to check } \\
\text { my site out as I'm developing it, so I didn't realize that } \\
\text { my overall pages weren't centering properly on wide- } \\
\text { screen monitors. }\end{array}$ \\
\hline & Asking for help & $\begin{array}{l}\text { My site was supposed to have a header, I made one in } \\
\text { gimp, but I couldn't get it to work. The bars overlap } \\
\text { when the window was re-sized, I don't know to fix } \\
\text { either. }\end{array}$ \\
\hline & $\begin{array}{l}\text { Clarifying earlier state- } \\
\text { ments }\end{array}$ & $\begin{array}{l}\text { Please don't take it as I'm being too critical on your } \\
\text { site. I just want you to get a good grade. }\end{array}$ \\
\hline & $\begin{array}{l}\text { Providing help including } \\
\text { examples or codes }\end{array}$ & $\begin{array}{l}\text { The pictures seem to be distorted and mis- } \\
\text { proportioned. You could also try using: } \\
\text { p \{ min-width:1024px; } \\
\text { which would make the scrollbar at the bottom go } \\
\text { away for people with lower resolutions. }\end{array}$ \\
\hline
\end{tabular}




\section{Discussion and Recommendations}

According to Tsai et al. (2011), motivation comes from the students' own interest in the material, their receiving good grades for the assignments, and recognition from others. In this study, students were allowed to create a website of their choice. This choice provided students with a sense of ownership of their websites, which also added to student motivation (Tsai et al., 2011). Based on the overall responses of the students, in general this peer evaluation activity proved to be a meaningful and effective way to evaluate student websites. After all, peer evaluation cannot be done by a single student and can only be done by many students working together.

Our findings about online website peer evaluation suggest that wikis can effectively support online peer evaluation in online courses. Most students had a positive learning experience and were comfortable in using wikis for this peer evaluation task. Students who were new to wikis before the peer evaluation activity also felt more comfortable with the technology by the end of the semester. They were interested in receiving feedback from others regarding their websites and appreciated having the peer evaluation opportunity which could identify potential issues and could help them improve their websites before final grading by the instructor. This peer evaluation activity not only allowed the students to fix issues and make improvements to their websites, but it also helped students learn the website evaluation skills through a meaningful and authentic learning activity. The results of the study in this online website development course confirm earlier findings that the collaborative nature of the task and task authenticity are success factors in using wikis (Bower et al., 2006; Zha, Kelly, Park, \& Fitzgerald, 2006). Thus, the author recommends that instructors in other course contexts conduct a preliminary task analysis to determine if their chosen tasks are both necessary and appropriate for peer evaluation.

Our study in this online website development course also reveals some issues in the peer evaluation process that prove that careful planning in group formation and a coordination of effort are needed to make the group peer evaluation activity successful. Knight and Steinbach (2011) made specific recommendations for instructors considering the implementation of peer review in an online course. They recommended that instructors identify and define the process in advance of the start of the course and do extra communicating with online students during the peer review process.

That way, instructors can better take students' class performance into account when assigning the students into groups. In our study, students were randomly allocated into groups in which their group members performed a peer evaluation of their websites. As could be expected, some groups were not as productive as other groups. In a future class, the author will attempt to assign peers into groups based on their prior class performance (such as their grade progress in the class) to ensure that at least one or two 'good' students will be in each group.

On the other hand, the group needs to determine who will be responsible for setting up the wiki initially and how to organize the postings on the group wiki, in order to facilitate the peer evaluation as early as possible. Each member also needs to ensure that a student's name is entered when he or she makes a post on the wiki pages (if this is not an anonymous evaluation). In addition, procrastination is a common problem with group work. Research shows that it is easier to procrastinate in an online learning situation as compared to a traditional face-to-face classroom (Elvers, Polzella, \& Graetz, 2003). Although most students were motivated to participate in this peer evaluation activity early, the author felt that some motivational strategies (such as giving a grading bonus to the best performer, sending out email reminders about both the importance of completing the reviews on-time (Knight \& Steinbach, 2011), and requesting substantial, thoughtful comments) could be used to help overcome the procrastination challenge. Based on the teaching experience taken from this study, the author recommends that instructors adopt motivational strategies (such as giving a grading bonus for the best peer evaluator in each group) and monitor 
student participation throughout the online peer evaluation process in order to better engage students in the peer evaluation process. The author also recommends that instructors advise students to set up email updates or to create RSS subscriptions to their group wiki site so that members can get instant notifications when there are any changes to pages, discussions, or files in the group's wiki.

\section{Conclusion}

Meaningful interaction or collaboration among learners is an important part of any educational course. The ABET (Accreditation Board for Engineering and Technology) Computing Accreditation Commission, which is responsible for accrediting programs in Computer Science, Information Technology, and Information Systems, lists a number of attributes that graduates of any computing program are expected to possess at the time of graduation (Ekstrom et al., 2006). Some of the attributes include:

- An ability to design, implement, and evaluate a computer-based system, process, component, or program to meet desired needs

- An ability to function effectively in teams to accomplish a common goal

As teamwork is a highly valued skill, it is necessary for instructors to help their students develop teamwork skills through hands-on activities. Our experience has proven that using wikis to conduct peer evaluation in a web development course is a meaningful and authentic learning task. The author hopes that the experiences shared in this paper will benefit other faculty who teach similar courses in online or distance learning formats.

Unlike other peer evaluation software tools or using discussion forums in a course management system such as Blackboard where students have little control over the way peer evaluation could be conducted, the introduction of wikis into the peer evaluation process can offer students an opportunity to conduct peer evaluation in their own way. This change may change students' perceptions of what online learning is about (Grierson, Nicol, Littlejohn, \& Wodehouse, 2004). After all, a course management system is not the only platform for online courses; in fact, it can be ineffective under some circumstances. Web 2.0 tools (such as wikis) can be strong supplements to course management systems, in some cases. This paper provides some evidence of the ways that wikis can be used to help faculty conduct peer evaluation activities in an online environment and contributes to the body of evidence regarding the use of wikis in online education.

For future research, the author plans to conduct a comparative study of two groups of students. One group will still use wikis for the peer evaluation. Another group will use the discussion forum in Blackboard for peer evaluation. As a result, the author can compare the two approaches in terms of student learning experience. In addition, the author will measure the learning style preference of these students. Learning style preferences tend to influence students' success or lack of success in particular courses or programs of study (Park et al., 2010). The author is interested in assessing whether there is a relationship between a student's learning style preference and his or her level of participation and contribution to peer evaluation in the online learning environment.

\section{Acknowledgement}

The author would like to thank the anonymous reviewers for their valuable comments and suggestions to improve the paper. In addition, the author would like to thank the editor Dr. John Beachboard for very constructive and detailed comments and editing on this paper. 


\section{References}

Bower, M., Woo, K., Roberts, M. \& Watters, P.A. (2006). Wiki pedagogy - A tale of two wikis. Paper presented at the 7th International Conference on Information Technology Based Higher Education and Training (ITHET 06), Sydney, Australia.

Cho, K., \& Schunn, C. (2005). Scaffolded writing and rewriting in the discipline: A Web-based reciprocal peer-review system. Computers and Education, 48(3), 409-426.

Dishaw, M., Eierman, M. A., Iversen, J. H., \& Philip, G. C. (2011). Wiki or Word? Evaluating tools for collaborative writing and editing. Journal of Information Systems Education, 22(1), 43-54.

De Volder, M., Rutjens, M., Slootmaker, A., Kurvers, H., Bitter, M., Kappe, R., Roossink, H., de Goeijen, J., \& Reitzema, H. (2007). Espace: A new Web-tool for peer assessment with in-built feedback quality system. Proceedings of ABR \& TLC Conference 2007, Hawaii, USA (2007).

Elgort, I., Smith, A. G., \& Toland, J. (2008). Is wiki an effective platform for group course work? Australasian Journal of Educational Technology, 24(2), 195-210.

Elvers, G. C., Polzella, D. J., \& Graetz, K. (2003). Procrastination in online courses: Performance and attitudinal differences. Teaching of Psychology, 30(2), 159-162

Ekstrom, J., Gorka, S., Kamali, R., Lawson, E., Lunt, B., Miller, J., \& Reichgelt, H. (2006). The information technology model curriculum. Journal of Information Technology Education, 5, 343-361. Retrieved from http://www.jite.org/documents/Vol5/v5p343-361Ekstrom155.pdf

Grierson, H., Nicol, D., Littlejohn, A., \& Wodehouse, A. (2004). Structuring and sharing information resources to support concept development and design learning. Paper presented at the Network Learning Conference, Exeter, UK, pp. 572-579.

Hamer, J., \& Sword, H. (2007). The Aropa project: A study of peer assessment \& student learning, Magazine of Centre for Academic Development, 1.

Kane, G. C., \& Fichman, R. G. (2009). The shoemaker's children: Using wikis for information systems teaching, researching and publication. MIS Quarterly, 33(1), 1-17.

Knight, L., \& Steinbach, T. (2011). Adapting peer review to an online course: An exploratory case study. Journal of Information Technology Education, 10, 81-100. Retrieved from http://www.jite.org/documents/Vol10/JITEv10p081-100Knight942.pdf

Lending, D. (2010) Using a wiki to collaborate on a study guide, Journal of Information Systems Education, 20, 1 .

Li, L.. \& Steckelberg, A. L. (2005). Peer Assessment Support System (PASS). Tech Trends: Linking Research \& Practice to Improve Learning, 49(4), 80-84. Retrieved April 17, 2008, from Academic Search Premier: http://www.ebsco.com

Mirielli, E. J. (2007). Using peer-evaluation in a website design course. Journal of Computing Sciences in Colleges, 22(4), 14-21.

Otter, M. E., Whittaker, S. \& Spriggs, S. (2009). Using wikis and peer evaluation to teach medical students how to find and assess evidence based resources: A pilot study. New Review of Academic Librarianship, 15(2), 187-205.

Park, C. L., Crocker, C., Nussey, J., Springate, J., \& Hutchings, D. (2010). Evaluation of a teaching tool wiki - in online graduate education. Journal of Information Systems Education, 21(3), 313-321.

Raman, M., Ryan, T., \& Olfman, L. (2005). Designing knowledge management systems for teaching and learning with wiki technology. Journal of Information Systems Education (JISE), 16(3), 311-320.

Roussinos, D., \& Jimoyiannis, A. (2011). Blended collaborative learning through a wiki-based project: A case study on students' perceptions. International Journal of Digital Literacy and Digital Competence (IJDLDC), 2(3), 15-30. 
Skeele, R. (2009). Peer assessment: A strategy for learning in a technology driven environment. In G. Siemens \& C. Fulford (Eds.), Proceedings of World Conference on Educational Multimedia, Hypermedia and Telecommunications 2009 (pp. 3091-3099). Chesapeake, VA: AACE.

Snodgrass, R. (2006). Single- versus double-blind reviewing: An analysis of the literature. SIGMOD Record, 35(3), S. 8-19.

Thomas, T., Davis, T., \& Kazlauskas, A. (2007). Embedding critical thinking in IS curricula. Journal of Information Technology Education, 6, 327-346. Retrieved from http://www.jite.org/documents/Vol6/JITEv6p327-346Thomas253.pdf

Tsai, W.T., Li, W., Elston, J., \& Chen, Y. (2011). Collaborative learning using wiki web sites for computer science undergraduate education: A case study. IEEE Transactions on Education, 54(1), 114-124.

Wessa, P., \& De Rycker, A. (2010). Reviewing peer reviews - A rule-based approach. International Conference on E-Learning, 408-418.

Zha, S., Kelly, P., Park, M. K., \& Fitzgerald, G. (2006). An investigation of communicative competence of ESL students using electronic discussion boards. Journal of Research on Technology in Education, $38(3), 349-367$.

\section{Appendix}

\section{Instruction for the Website Peer Review Assignment}

\section{Objective}

- Conduct the website evaluation

- Become familiar with Wikis

- Use technology to support collaboration

You are going to use a novel approach (the Wiki approach) to conduct the peer review of the websites in your group. This activity will help you become familiar with both the wiki and the peer review process. Please take this collaborative activity seriously. Your participation and contribution in this website peer review activity will be graded. Below are the required steps:

1. Create your group wiki at http://www.wikispaces.com/

2. Each member in the group should post his or her project website's URL on the group wiki. Afterwards, each member will work as a reviewer and give feedback/comments on other members' websites. It means that you will need to evaluate everyone else's website in your group. Your group should discuss and find an effective way to conduct this peer review activity using the wiki.

3. Your feedback should be based on the following evaluation questions: how well is the material presented? Is the information clear? Is the website easy to navigate? Is the site aesthetically pleasing? What improvements still need to be made to the site?

4. Each member should complete their website evaluation before 8am this Saturday.

5. Then each member should read and evaluate the feedback from each reviewer. Be noted that the comments you received may not always be valid or useful to you. Afterwards, please modify/update your website based on the feedback. You should consider all the comments you received, but you are not required to address all comments (due to time limitation, invalid comments, etc). Just try your best to improve your website! 
6. At last, I suggest that you respond to each reviewer's feedback respectively on the group wiki. In your reply, you are encouraged to address specific points raised by each reviewer. This step concludes the peer review process for this assignment. However, your group is welcome to continue this peer review process until everyone is satisfied.

The whole assignment should be completed by $8 \mathrm{am}$ next Wednesday.

\section{Biography}

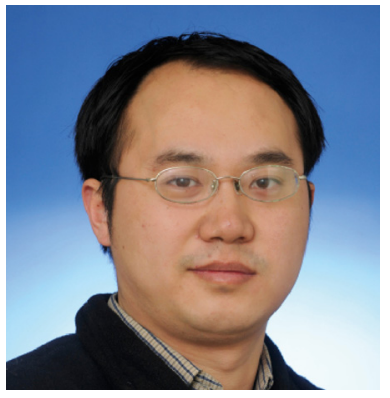

Wu He is an Assistant Professor in the Department of Information Technology and Decision Sciences at Old Dominion University, USA. $\mathrm{He}$ holds a $\mathrm{PhD}$ in Information Science (University of MissouriColumbia, USA). His research interests include Data Mining, Databases, Case-based Reasoning, Knowledge Management and Information Technology Education. 